\title{
Ionic Liquid Assisted Extraction of Nitrogen and Sulphur-Containing Air Pollutants from Model Oil and Regeneration of the Spent Ionic Liquid
}

\author{
Ikenna Anugwom ${ }^{1}$, Päivi Mäki-Arvela ${ }^{1}$, Tapio Salmi ${ }^{1}$, Jyri-Pekka Mikkola ${ }^{1,2}$ \\ ${ }^{1}$ Industrial Chemistry and Reaction Engineering, Process Chemistry Centre, Åbo Akademi University, Turku, Finland; ${ }^{2}$ Technical \\ Chemistry, Department of Chemistry, Chemical-Biological Center, Umeå University, Umea, Sweden. \\ Email: ianugwom@abo.fi, jyri-pekka.mikkola@chem.umu.se
}

Received April 21 $1^{\text {st }}, 2011$; revised June $9^{\text {th }}, 2011$; accepted July $16^{\text {th }}, 2011$.

\begin{abstract}
Removal of air pollutants, such as nitrogen and sulphur containing compounds from a model oil (dodecane) was studied. An ionic liquid (1-ethyl-3-methylimidazolium chloride $\left[C_{2} \mathrm{mim}\right][\mathrm{Cl}]$ ) was used as an extractant. Liquid-liquid extraction by using 1-ethyl-3-methylimidazolium chloride $\left[\mathrm{C}_{2} \mathrm{mim}\right][\mathrm{Cl}]$ was found to be a very promising method for the removal of $\mathrm{N}$ - and S-compounds. This was evaluated by using a model oil (dodecane) with indole as a neutral nitrogen compound and pyridine as a basic nitrogen compound. Dibenzothiophene (DBT) was used as a sulphur compound. An extraction capacity of up to $90 \mathrm{wt} \%$ was achieved for the model oil containing pyridine, while only $76 \mathrm{wt} \%$ of indole in the oil was extracted. The extraction capacity of a model sulphur compound DBT was found to be up to 99 wt\%. Regeneration of the spent ionic liquid was carried out with toluene back-extraction. A 1:1 toluene-to-IL wt ratio was performed at room temperature. It was observed that, for the spent ionic liquid containing DBT as a model compound more than $85 \mathrm{wt} \%$ (corresponding $3852 \mathrm{mg} / \mathrm{kg}$ ) could be removed from the oil. After the second regeneration cycle, 86 wt\% of the DBT was recovered from the ionic liquid to toluene. In the case of indole as the nitrogen containing species, more than $99 \mathrm{wt} \%$, (corresponding to $2993 \mathrm{mg} / \mathrm{kg}$ ) of the original indole was transferred from the model oil to the ionic liquid. After the first-regeneration cycle of the spent ionic liquid, $54 \mathrm{wt} \%$ of the indole-in-IL was transferred to toluene. Thus, both extractions of nitrogen and sulphur model compounds were successfully carried out from model oil and the back-extraction of these compounds from the ionic liquids to toluene demonstrated the proved the concept of the regeneration point of view.
\end{abstract}

Keywords: Ionic Liquids, Extraction, Air Pollutants, Nitrogen Compound, Sulfur Compounds

\section{Introduction}

Developments in the field of separation of pollutants, such as nitrogen and sulphur-containing compounds in the refinery industry have been experiencing a rapid growth due to more and stricter environmental protection regulations on the release of these pollutants from transportation fuels. Ionic liquids on the other hand are potential alternative solvents for the separation of aromatic hydrocarbons (benzene, toluene, ethyl benzene) from $\mathrm{C}_{4}$ to $\mathrm{C}_{10}$ aliphatic hydrocarbon mixtures [1].

The prospect of ionic liquids as alternative solvents to substitute less desirable organic media is under intensive research. The low vapor pressure and ability to adjust the physical and chemical properties of ionic liquids by selection of the cations and anions, makes them attractive for a wide range of applications. For example, ionic liquid have already illustrated their potential as alternative solvents and reaction media [2-5]. Furthermore, ionic liquids have been applied in solvent extraction processes and in gas separations $[6,7]$.

Nitrogen compounds are harmful impurities in petroleum products. In liquid fuels, nitrogen compounds act as precursors for nitrogen oxides $\left(\mathrm{NO}_{\mathrm{X}}\right)$, which are environmental pollutants. Nitrogen compounds are known to be poisons for acidic and metallic refinery catalysts and, thus, they cause problems in the petroleum hydrotreatment. Nitrogen compounds have also been considered to be responsible for the color and gum formation as well as for formation of deposits. Nitrogen compounds in petroleum products, when combusted, have carcinogenic and mutagenic properties [8]. Furthermore, the adsorption of 
nitrogen-compounds on catalysts is higher compared to that of sulphur-compounds, even though their reactivity is lower. Thus, as the concentrations of the refractory sulphur compounds in the oil have been lowered via normal hydrodesulphurization (HDS) process, the nitrogen-compounds present in the oil could inhibit the HDS process through their competitive adsorption on the catalyst surface [1,9]. The removal of such HDS catalyst inhibitors could promote the improvement of the HDS conditions and thus, contribute in reducing the difficulties of meeting the strict emission specifications in the transportation fuels.

Non-catalytic processes for the selective removal of $\mathrm{N}$-compounds have been studied, whereby basic Ncompounds, such as pyridine and quinoline, have been removed by using ion-exchange resins [9]. Additionally, liquid-liquid extraction of nitrogen and sulphur compounds by using volatile carboxylic acids [10] and ionic liquids as extracting solvents have been demonstrated $[1,2]$.

Liquid-liquid extraction has been extensively used in industrial in the separation and purification of aromatic hydrocarbon, because of severe operation conditions and straightforward processes [11]. The use of conventional polar organic compounds such as glycol or sulfolane has been extensively applied for commercial extraction of aromatic hydrocarbons from aromatic-aliphatic mixtures [12]. However, due to the high volatilities of these chemicals, there are usually losses of extractants by evaporation. These organic compounds are generally toxic and flammable [12]. Liquid-liquid extraction has some general drawbacks as conventional polar organic compounds are used. It is of particular importance to develop novel extractants with high distribution coefficients, high selectivities and low solvent losses.

Ionic liquids are organic salts composed of organic cations and inorganic anions, and their melting points are under or at ambient temperatures. Ionic liquids are interesting due to their tuneable properties, making them suitable as reaction media and extraction solvents among other applications [13]. It should be noticed that ionic liquids have negligible vapour pressures and, thus, the regeneration of spent ionic liquids with minor solvent losses might be possible. Ionic liquids have high chemical and thermal stabilities and a wide liquidus range $[1,9$, $12,13]$.

The aim of this work was to investigate the liquid-liquid extraction of a model oil, dodecane, with an ionic liquid, 1-ethyl-3-methylimidazolium chloride $\left.\left(\left[\mathrm{C}_{2} \mathrm{mim}\right][\mathrm{Cl}]\right]\right)$. The model oil contained pyridine and indole as basic and neutral nitrogen compounds, respectively, whereas dibenzothiophene was used as sulphur compound (Figure 1).

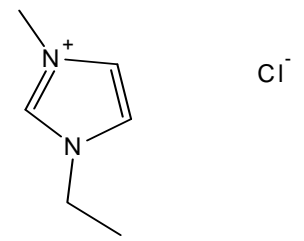

(a)<smiles>c1ccncc1</smiles>

(b)<smiles>c1ccc2[nH]ccc2c1</smiles>

(c)

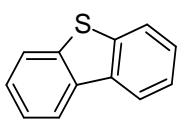

(d)

Figure 1. Extraction of dodecane with (a) an ionic liquid $\left[\mathrm{C}_{2}\right.$ mim] [Cl]. Following compounds were used as model $\mathrm{N}$ and S containing compounds: (b) pyridine, (c) indole, (d) dibenzothiophene.

\section{Experimental Section}

\subsection{Sample Preparation}

The model oil used was either pure dodecane or 1:1 dodecane- toluene mixture (99.5 wt\%, J.T: Baker) $(98 \mathrm{wt} \%$, Fluka), while indole (99 wt\%, Aldrich) and pyridine (99 $\mathrm{wt} \%$, Acros) were used as nitrogen-containing compounds, respectively. Dibenzothiophene (DBT) ( $99 \mathrm{wt} \%$, Sigma-Aldrich) served as a sulphur containing compound. The model oil contained $3000 \mathrm{ppm}$ of $\mathrm{N}$-compound, whereas the concentration of the sulphur compound was $4545 \mathrm{ppm}$. The toluene ( $99.5 \mathrm{wt} \%$, J.T: Baker) was used as the back-extraction liquid for ionic liquid recovery. The ionic liquid was a commercially available 1-ethyl-3methyl-imidazolium chloride $\left[\mathrm{C}_{2} \mathrm{mim}\right][\mathrm{Cl}](95 \mathrm{wt} \%$, Merck, water content was $1.4 \mathrm{wt} \%$ ) and it was used as such. The samples were prepared by dissolving the required amounts of the $\mathrm{N}$ - or S-containing compounds into $20 \mathrm{ml}$ of dodecane. The effect of the aromatics was tested by dissolving the required amount of $\mathrm{N}$ - or S-compound into a mixture of dodecane and toluene (1:1 wt-ratio, 20 $\mathrm{ml})$.

\subsection{Extraction Procedure}

The extraction experiments were performed in $10 \mathrm{ml}$ vials, 
with the ionic liquid to model oil ratios of 1:1, 1:5 and $1: 10$. The ionic liquid-model oil mixture formed a two-phase sample, in which the top phase was the model oil and the lower phase was the ionic liquid. A PTFE magnetic stirrer unit with an IKA magnetic stirrer equipped with a thermocouple was used for the agitation and temperature control. The extraction was carried out at $60^{\circ} \mathrm{C}$ for $15 \mathrm{~min}$. The phases were separated after the experiment by decantation and the model oil was analyzed by GC. The ionic liquid was regenerated by back-extraction by using toluene, at room temperature. The ionic liquid to toluene ratio was 1:1 (vol.) in the back extraction experiment.

\subsection{Analytical Procedure}

The model oil was analyzed by gas chromatography (Agilent technologies 6890N network GC System with an on-column injector having a flame ionization detector (FID). The column used was Agilent 122-10A6, DB-Petro, (length $100 \mathrm{~m}$, internal diameter $250 \mu \mathrm{m}$ and film thickness $0.50 \mu \mathrm{m})$. The following temperature programme was used: $50^{\circ} \mathrm{C}\left(3.8^{\circ} \mathrm{C} / \mathrm{min}\right)-220^{\circ} \mathrm{C}(5 \mathrm{~min})$.

\section{Results and Discussions}

\subsection{Effect of an Aromatic Compound on the Extraction Capacity of the Ionic Liquid}

The effect of an aromatic compound present in the model oil for the extraction capacity is shown in Figure 2. The nitrogen content in the model oil was $3000 \mathrm{ppm}$. The extraction capacity of the ionic liquid for the removal of indole ( $\mathrm{N}$-compound 1) was reduced by $20 \%$ as the amount of aromatics in the model oil was increased to 50 $\mathrm{wt} \%$. In the case of pyridine ( $\mathrm{N}$-compound 2 ), the presence of aromatics in the model oil reduced the extraction capacity of the ionic liquid by $20 \%$ as well, compared to the case in the absence of aromatics Figure 3. Therefore, it is evident that the presence of aromatic compounds in the model oil decreases the extraction capacity of the ionic liquid. The presence of an aromatic compound in the sample affected the extraction capacity of the ionic liquid probably due to the fact that the ionic liquid exhibits a high affinity towards the aromatics. The origin of this affinity most probably resides in the $\mathrm{CH}-\pi$ interactions between the hydrogen in the ionic liquid ring and the aromatics [13]. An increase in the aromatic content of the model oil, therefore, reduces the extraction capacity of the ionic liquid as observed by Xie et al. [1]. The high extraction capacity of the ionic liquids for heterocyclic aromatic compounds has been reported by several authors [14-16]. It is suggested that the interactions of the ionic liquids with the aromatic compounds are linked to the electron pair-acceptor properties of the 1,3-dialkylimidazolinium rings. It was assumed that in the presence of a high concentration of aromatics, the extraction of other compounds is compromised due to the saturation of ionic liquids by aromatics. Thus, as the mass fraction of toluene in the hydrocarbon mixture was increased, the distribution coefficient for heterocyclic aromatic compounds decreased linearly as has been reported Xie et al. [1]. Analogously it was concluded that the ionic liquids (IL) exhibited a better extraction capacity of the model oil if no aromatic compounds were present.

\subsection{Effect of the Ionic Liquid to Oil Ratio}

The effect of the ionic liquid-to-oil ratio was investigated in the extraction of $\mathrm{N}$-compounds from the model oil. The extraction capacity improved as the ratio of IL-to-oil was increased, for indole Figure 4 and pyridine Figure 5, respectively. The extraction capacity also improved with an increase in the IL to oil ratio. A similar observation was reported by Zhao et al. [13], in which 1-butyl-3methylimidazolium chloride with aluminium chloride $\left(\left[\mathrm{C}_{4} \mathrm{mim}\right][\mathrm{Cl}] /\left[\mathrm{AlCl}_{3}\right]\right)\left([\mathrm{Cl}] /\left[\mathrm{AlCl}_{3}\right]\right.$ (ratio 0.35/0.65)) was used as an ionic liquid and the model oil contained $500 \mathrm{ppm}$ of DBT in n-dodecane. Four consecutive extractions were carried out at $60^{\circ} \mathrm{C}$ and a fresh ionic liquid was in each extraction. The model oil used by Eber et al. [2] and Bösmann et al. [14] contained $500 \mathrm{ppm}$ of DBT in dodecane and the extraction was carried out at room temperature [2,14]. The ionic liquid used by Eber et al. [2] was 1-butyl-3-methyl-imidazolium octylsulfate $\left(\left[\mathrm{C}_{4}\right.\right.$ $\left.\mathrm{mim}]\left[\mathrm{OcSO}_{4}\right]\right)$. Generally, they used a mixing contact time 15 min between ionic liquid and oil $[2,14]$. The model oil in the current study was a mixture containing

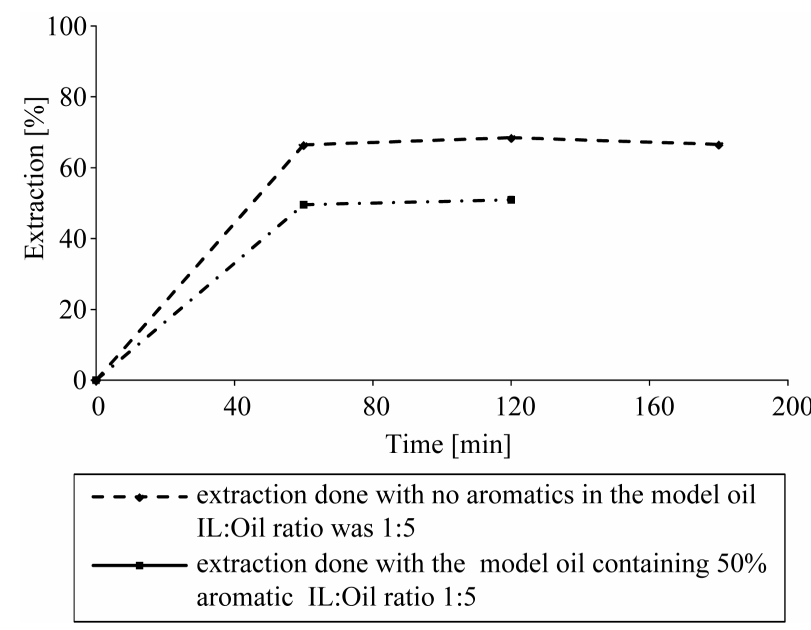

Figure 2. Extraction of the model oil containing indole as the N-compound with $\mathrm{IL}\left[\mathrm{C}_{2} \mathrm{mim}\right][\mathrm{Cl}]$ at $60^{\circ} \mathrm{C}$. 


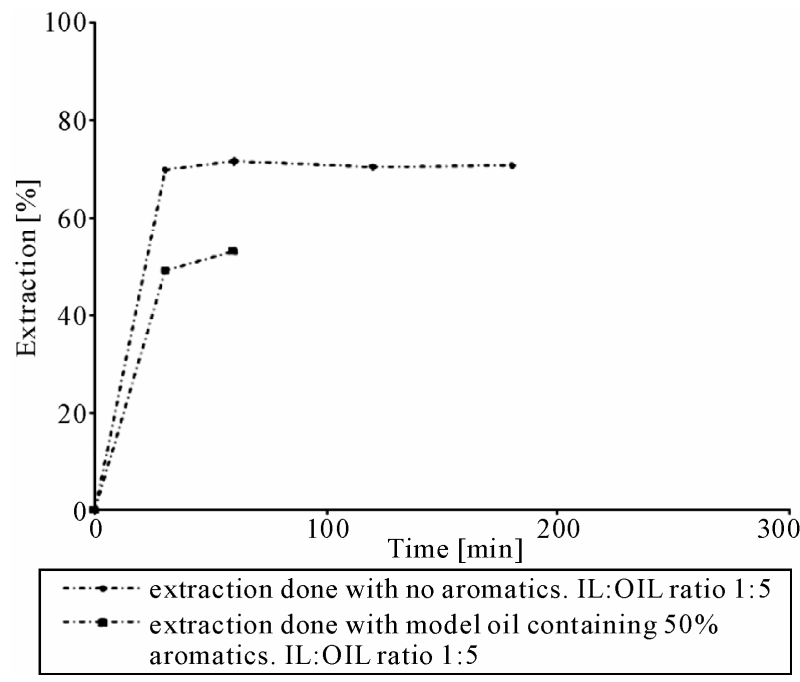

Figure 3. Extraction of the model oil containing pyridine as the $\mathrm{N}$-compound with $\mathrm{IL}\left[\mathrm{C}_{2} \mathrm{mim}\right][\mathrm{Cl}]$ at $60^{\circ} \mathrm{C}$.

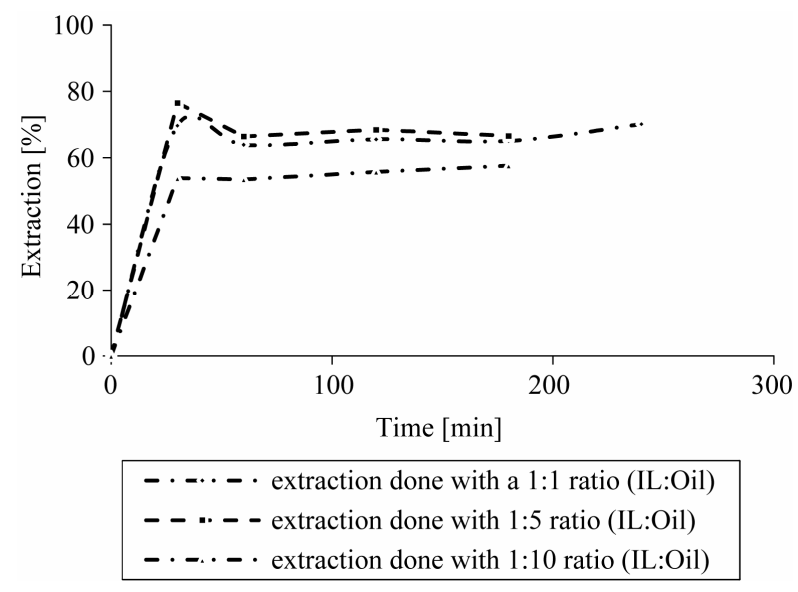

Figure 4. Extraction of the model oil containing indole as the $\mathrm{N}$-compound with $\mathrm{IL}\left(\left[\mathrm{C}_{2} \mathrm{mim}\right][\mathrm{CI}]\right)$ at $60^{\circ} \mathrm{C}$.

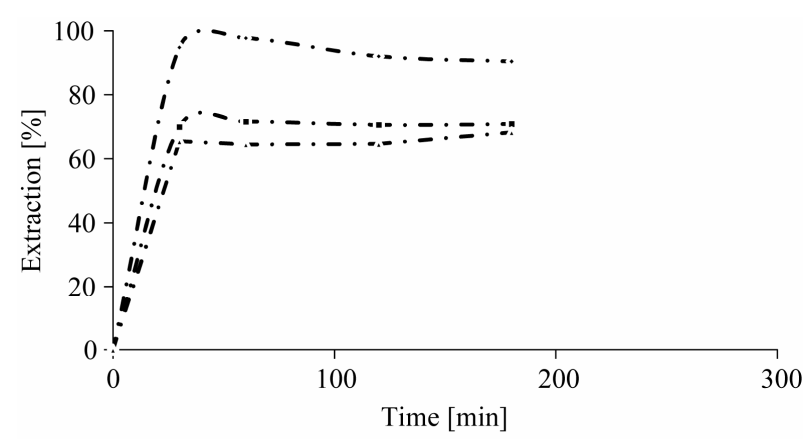

$$
\begin{aligned}
& -\cdots \cdots-\cdot \text { extraction done with } 1: 1 \text { ratio (IL:Oil) } \\
& -\cdots \cdots-\cdot \text { exraction done with 1:5 ratio (IL:Oil) } \\
& \ldots-\cdots-\cdot \text { extraction done with } 1: 10 \text { ratio (IL:Oil) }
\end{aligned}
$$

Figure 5. Extraction of the model oil containing pyridine as the $\mathrm{N}$-compound with $\mathrm{IL}\left(\left[\mathrm{C}_{2} \mathrm{mim}\right][\mathrm{Cl}]\right)$ at $60^{\circ} \mathrm{C}$.
$3000 \mathrm{ppm}$ of the nitrogen compound (indole or pyridine) in dodecane. Different ionic liquid to oil ratios were selected 1:1, 1:5, 1:10 (wt-ratio) and the extraction conditions were allowed to be the same in all cases: temperature was $60^{\circ} \mathrm{C}$ while 15 min mixing contact time between the oil and IL was used (Figures 4 and 5).

The extraction of the model oil containing indole as the nitrogen compound was performed at $60^{\circ} \mathrm{C}$ and the IL-to oil ratio (wt) was 1:5. In equilibrium, $70 \%$ of the nitrogen compound was removed (Figure 4). In the case of a 1:1 IL-to-oil ratio $76 \%$ of indole was removed in equilibrium at $60^{\circ} \mathrm{C}$. This is an indication that a higher IL-to-oil ratio does not improve the extraction effectiveness prominently. Moreover, thinking about potential large-scale process, 1:5 IL to oil ratio is already rather high.

The extraction capacity of pyridine was strongly affected, when a larger amount of the ionic liquid was used. When the model oil containing pyridine as a nitrogen compound was extracted (1:5 IL-to-Oil wt-ratio) at $60^{\circ} \mathrm{C}$, $70 \%$ of the nitrogen compound was removed at equilibrium. In the case that the IL to oil ratio (wt-ratio) was increased from 1:5 to $1: 1$ (wt-ratio), $90 \%$ of pyridine was removed from the model oil at equilibrium. It is evident that higher IL to oil ratio did not affect too much the extraction capacity and, therefore, a 1:5-ratio seems to be more appropriate however, already this ratio would result in big liquid streams to be pumped around in large scale applications.

The results from the present work cannot be directly compared to the results presented in literature $[1,2,13,14]$. Several factors have been reported to improve the extraction capacity of ionic liquids, such as lowering the viscosity of the ionic liquid [17] as well as selection of ionic liquid with a longer alkyl chain in the cation part of the ionic liquid [17]. For instance, 1-butyl-3-methylimidazolium chloride [1] has a longer alkyl length compared to the present study, in which 1-ethyl-3-methylimidazolium chloride was used as an extractant. The reason why we wanted to study extraction with a cation containing a shorter alkyl chain was simple; the goal was to investigate, if an ionic liquid with more favorable toxicity profile could be used, since butyl-imidazolium derivatives are rather toxic. The lengths of the alkyl substitutes, on both the cation and the anions of the IL, influence the extraction efficiency of the ionic liquid [17]. One of the biggest limitations for the use of ionic liquids lies in the fact that they often have quite high viscosities. In this work, 1-ethyl-3-methylimidazolium chloride was used. However, 1-butyl-3-methylimidazolium chlorides, 1-butyl3-methylimidazolium chloride, 1-butyl-3-methylimidazolium trifluoromethylsufonate that were used by the other authors [1,2,14]; all have viscosities within the 
same range [17], typically 14 - $48 \mathrm{cP}$. A lower viscosity of an ionic liquid leads to more effective mass transfer, thus, enhancing the extraction rate.

\subsection{Extraction of S-Compounds from the Model Oil Using Ionic Liquid}

The extraction of dibenzothiophene as the sulphur compound in the model oil was carried out with $\left[\mathrm{C}_{2} \mathrm{mim}\right][\mathrm{Cl}]$ as the ionic liquid Figure 6. The extraction was carried out for $15 \mathrm{~min}$ at $60^{\circ} \mathrm{C}$, and the IL to oil ratio-wt was 1:1. The results demonstrated that the concentration of the S-compound in the model oil was reduced by $99 \%$ after a completed extraction. This result demonstrated that the extraction of dibenzothiophene from the model oil, with 1-ethyl-3-methylimidazolium chloride $\left(\left[\mathrm{C}_{2} \mathrm{mim}\right][\mathrm{Cl}]\right)$ was successful.

\subsection{Regeneration of Spent Ionic Liquid}

The regeneration of the spent ionic liquid was carried out after the extraction of the N-compound from the model oil. After the extraction of the model oil, the nitrogen content of the model oil was reduced from the original level of $3000 \mathrm{mg} / \mathrm{kg}$ to $6.7 \mathrm{mg} / \mathrm{kg}$ (very close to $100 \%$ ). Thus, the ionic liquid contained after the extraction 2993 $\mathrm{mg} / \mathrm{kg}$ nitrogen in the form of indole Figure 7. The concentration of the $\mathrm{N}$-compound in the ionic liquid after the regeneration cycle one with toluene was found to be $1600 \mathrm{mg} / \mathrm{kg}$ and, thus, the nitrogen content was reduced by $46 \%$. After the second regeneration cycle with toluene, the indole content in the IL was reduced to $1300 \mathrm{mg} / \mathrm{kg}$, corresponding to $54 \%$ of the original amount Figure 7.

The regeneration of the spent ionic liquid, it was observed that, for the spent ionic liquid containing DBT as a model sulphur compound contained $4532 \mathrm{mg} / \mathrm{kg}_{\mathrm{IL}}$ DBT after the extraction. After the first regeneration cycle using toluene as extractant in back-extraction in a 1:1 wt-ratio toluene-to-IL, over $85 \mathrm{wt} \%$ (corresponding 3852 $\mathrm{mg} / \mathrm{kg}$ ) of DBT could be removed from the IL by this method. After the second regeneration cycle, $86 \mathrm{wt} \%$ of the DBT was recovered from the ionic liquid to toluene Figure 8.

\section{Conclusions}

In the present work, extraction of sulphur-and nitrogen-containing air pollutants from model oil, dodecane or dodecane-toluene (1:1 wt ratio) with ionic liquids was demonstrated. The effect of the oil-to-ionic liquid ratio and the effect of the aromatic content were studied. Furthermore, the spent ionic liquids were regenerated by back-extraction.

The effect of the presence of aromatic compounds in the model oil was investigated during the extraction with

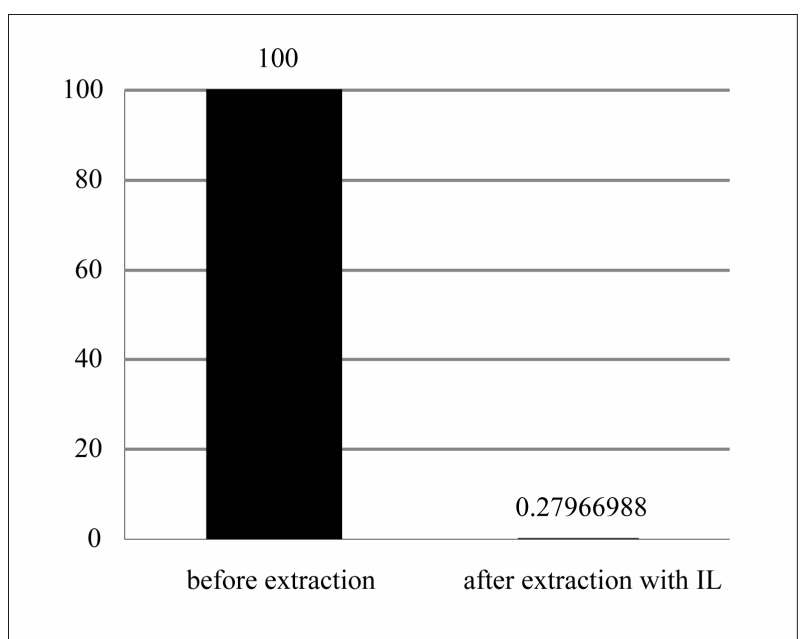

Figure 6. The extraction of S-compound (DBT) from the model oil. $\mathrm{IL}\left[\mathrm{C}_{2} \mathrm{mim}\right][\mathrm{Cl}]$ at $60^{\circ} \mathrm{C}$ in $\mathrm{IL}$ to oil ratio1:1(wt).

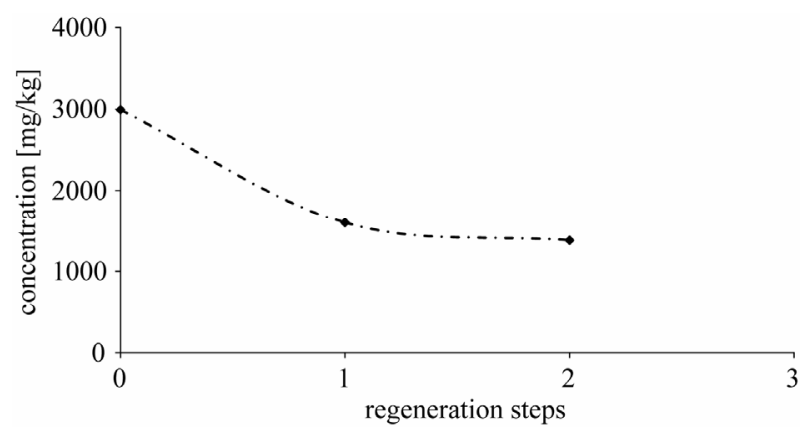

Figure 7. The concentration of the $\mathrm{N}$-compound (indole) in spent IL. Toluene was used for IL regeneration at $25^{\circ} \mathrm{C}$.

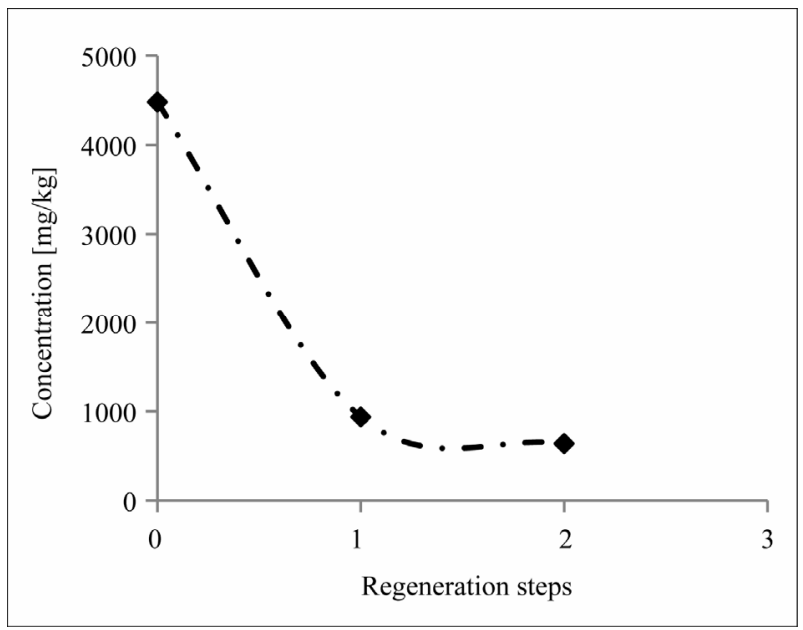

Figure 8. The concentration of S-compounds (DBT) in IL. Toluene was used for $\mathrm{IL}$ regeneration at $25^{\circ} \mathrm{C}$.

ionic liquid. The model oil contained $3000 \mathrm{ppm}$ nitrogen and $4545 \mathrm{ppm}$ sulphur compounds, respectively. The 
results from the extraction of $\mathrm{N}$-compounds and S-compounds in the model oil with the ionic liquids at $60^{\circ} \mathrm{C}$ both in the absence and in the presence of aromatic compounds, revealed that the nitrogen content starting from indole was reduced by $76 \%$ from the model oil in the absence of aromatic compound, whereas in the presence of an aromatic compound, the nitrogen concentration was reduced only by $50 \%$. Analogously, as pyridine was the nitrogen compound, the content of the nitrogen compound was reduced by $70 \%$ from the model oil when aromatic-free oil, and in the presence of aromatic compounds only $55 \%$ reduction of the nitrogen content was achieved.

The effect of the ionic liquid-to-oil ratio was investigated during the extraction of the $\mathrm{N}$-and S-compounds from the model oil. The model oil samples were prepared so that they contained equal concentrations of the nitrogen and sulphur compounds as being present in a real sample heavy fuel oil (from refinery). The $\mathrm{N}$ - and S-compounds were extracted with the ionic liquid at $60^{\circ} \mathrm{C}$. The nitrogen concentration using indole as a model compound was reduced by $90 \%$ when the ratio of ionic liquid-to-oil was $1: 1$ and by $65 \%$ when the ionic liquid-to-oil ratio was 1:5. The reduction of the pyridine content was $60 \%$ when the ionic liquid-to-oil ratio was $1: 10$.

Extraction of model oil with an ionic liquid revealed that this method is suitable for removal of sulphur and nitrogen compounds for fuel applications.

The results from the regeneration and reuse of the spent ionic liquid revealed that the concentration of the $\mathrm{N}$-compound and S-compound decreased by $54 \%$ and by $86 \%$, respectively, showing that continuous operation with extraction and regeneration would be desired.

\section{Acknowledgements}

This work is part of the activities at the Åbo Akademi University Process Chemistry Centre within the Finnish Centre of Excellence Programme (2000-2011) appointed by the Academy of Finland. The work was carried out by financial support from Neste Oil Oyj.

\section{REFERENCES}

[1] L.-L. Xie, A. Favre-Reguillon, X. Wang, X. Fu, S. Pellet-Rostaing, G. Toussaint, C. Geantet, M. Vrinat and M. Lemaire, "Selective Extraction of Neutral Nitrogen Compounds Found in Diesel Feed by 1-Butyl-3-methyl-imidazolium Chloride," Green Chemistry, Vol. 10, No. 5, 2008, pp. 524-531.

[2] J. Eber, P. Wasserscheid and A. Jess, "Deep Desulphurization of oil Refinery Streams by Extraction with Ionic Liquids," Green Chemistry, Vol. 6, No. 7, 2004, pp. 316-
322.

[3] A. B. Pereiro, J. L, Legido and A. Rodriguez, "Physical Properties of Ionic Liquids Based on 1-Alkyl-3-methylimidazolium Cation and Hexafluorophosphate as Anion and Temperature Dependence," J. Chem. Thermos. Vol. 39, 2007, pp. 1168-1175.

[4] M. J. Earle and K. R. Seddon, "Green Solvents for the Future," Pure and Applied Chemistry, Vol. 72, No. 7, 2000, pp. 1391-1398.

[5] R. D. Rogers and K. R. Seddon, "Ionic Liquids as Green Solvents," Oxford University Press, Washington D.C., 2003.

[6] I. Merdrignac, F. Behar, P. Briot, M. Vandenbroucke, "Quantitative Extraction of Nitrogen Compounds in Oils: Atomic Balance and Molecular Composition," Energy \& Fuels, Vol. 12, No. 6, 1998, pp. 1342-1355.

[7] M. E. Prudlch, D. C, Cronauer, R. F. Vogel and J. Solash, "Shale Oil Denitrogenation with Ion Exchange. 1. Process Concept and Modeling," Industrial and Engineering Chemistry Process Design and Development, Vol. 25, 1986, pp.742-746.

[8] J. Qi, Y. Yan, Y. Su, F. Quand and Y. Dai, "Extraction of Nitrogen Compounds from Catalytically Cracked Diesel Oil with a Volatile Carboxylic Acid Based on Reversible Chemical Complexation," Energy \& Fuels, Vol. 12, No. 4, 1998, pp. 788-791.

[9] L. Alonso, A. Arce, M. Francisco, O. Rodriguez and A. Soto, "Gasoline Desulphurization Using Extraction with $\left[\mathrm{C}_{8} \mathrm{mim}\right]\left[\mathrm{BF}_{4}\right]$ Ionic Liquid," American Institute of Chemical Engineers Journal, Vol. 53, No. 12, 2007, pp. 31083115 .

[10] J. Zhang, C. Huang, B. Chen, P. Ren and Z. Lei, "Extraction of Aromatic Hydrocarbons from Aromatic/Aliphatic Mixtures Using Chloroaluminate Room-Temperature Ionic Liquids as Extractants," Energy \& Fuels, Vol. 21, 2007, pp. 1724-1730.

[11] H. Zhao, S. Xia and P. Ma, "Use of Ionic Liquids as 'Green' Solvents for Extraction," Journal of Chemical Technology \& Biotechnology, Vol. 80, No. 10, 2005, pp. 1089-1096.

[12] S. Zhang, Q. Zhang and C. Z. Zhang, "Extractive Desulphurization and Denitrogenation of Fuels Using Ionic Liquids," Industrial \& Engineering Chemistry Research, Vol. 43, No. 2, 2004, pp. 614-622.

[13] A. Agulyansky, L. Agulyansky and V. F. Travkin, "Liquid-Liquid Extraction of Tantalum with 2-Octanol," Chemical Engineering and Processing, Vol. 43, 10, 2004, pp. 1231-1237.

[14] A. Bösmann, L. Datsevich, A. Jess, A. Lauter, C. Schmitz and P. Wasserscheid, "Deep Desulphurization of Diesel Fuel by Extraction with Ionic Liquids," Chemical Communications, Vol. 23, 2001, pp. 2494-2495.

[15] J. G. Huddleston, A. E. Visser, W. M. Reichert, H. Willauer, G. Broker and R. Rogers, "Characterization and Comparison of Hydrophilic and Hydrophobic Room Temperature Ionic Liquids Incorporating the Imidazolium 
cation," Green Chemistry, Vol. 3, 2001, pp. 156-164.

[16] C. Chiappe and D. Pieraccini, "Ionic Liquids Solvent Properties and Organic Reactivity," Journal of Physical
Organic Chemistry, Vol. 18, No. 4, 2005, pp. 275-297.

[17] P. Wasserscheid and T. Welton, "Ionic Liquid in Synthesis," Wiley-VCH, Weinheim, 2006. 